\title{
Zoonotic tuberculosis and brucellosis in Africa: neglected zoonoses or minor public-health issues? The outcomes of a multi-disciplinary workshop
}

\section{T. MARCOTTY ${ }^{\star}$, F. MATTHYS ${ }^{\dagger}$, J. GODFROID ${ }^{\ddagger}$, L. RIGOUTS ${ }^{\S}$, G. AMENI ${ }^{\star}$, N. GEY VAN PITTIUS ${ }^{\star \star}$, R. KAZWALA ${ }^{\dagger \dagger}$, J. MUMA ${ }^{\star \star}$, P. VAN HELDEN ${ }^{\star \star}$, K. WALRAVENS ${ }^{\S \S}$,L. M. DE KLERK ${ }^{\star \uparrow}$, C. GEOGHEGAN ${ }^{\star \star \star}$, D. MBOTHA ${ }^{\dagger \dagger \dagger}$,

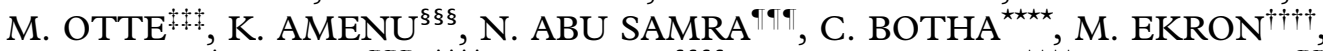

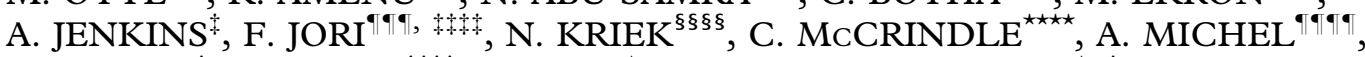 D. MORAR ${ }^{\ddagger}$, F. ROGER ${ }^{\dagger+1}$, E. THYS ${ }^{\star}$ and P. VAN DEN BOSSCHE ${ }^{\star}$,}

*Department of Animal Health, Institute of Tropical Medicine, Nationalestraat 155, 2000 Antwerp, Belgium

${ }^{\dagger}$ Department of Public Health, Institute of Tropical Medicine, Nationalestraat 155, 2000 Antwerp, Belgium

*Department of Veterinary Tropical Diseases, Faculty of Veterinary Science, University of Pretoria, P/Bag X04, Onderstepoort 0110, South Africa

${ }^{\S}$ Department of Microbiology, Institute of Tropical Medicine, Nationalestraat 155, 2000 Antwerp, Belgium

'Aklilu Lemma Institute of Pathobiology, P.O. Box 1176, Addis-Ababa, Ethiopia

${ }^{\star \star}$ Division of Molecular Biology and Human Genetics, Stellenbosch University, P/Bag X1, Stellenbosch 7602, South Africa

${ }^{\dagger}$ Department of Veterinary Medicine and Public Health, Sokoine University of Agriculture, P.O. Box 3000, Chuo Kikuu, Morogoro, Tanzania

*Department of Disease Control, School of Veterinary Medicine, University of Zambia, P.O. Box 32379, Lusaka, Zambia

${ }^{\S \S}$ Veterinary and Agrochemical Research Centre, Groeselenberg 99, 1180 Brussels, Belgium

" Military Veterinary Institute, P/Bag X11, Noordbrug 2522, South Africa

${ }^{\star \star \star}$ Department of Zoology, Faculty of Natural and Agricultural Sciences, University of Pretoria 0002, South Africa

${ }^{\dagger \dagger}$ Analabs Limited, P.O. Box 24780, Nairobi, Kenya

Ht Department of Cultural Anthropology and Development Sociology, Faculty of Social and

Behavioural Sciences, Leiden University, P.O. Box 9555, 2300 RB Leiden, Netherlands

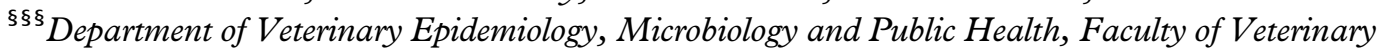
Medicine, Hawassa University, P.P. Box 5, Hawassa, Ethiopia

ฯฯ Department of Production Animal Studies, Faculty of Veterinary Science, University of

Pretoria, P/Bag X04, Onderstepoort 0110, South Africa

${ }^{\star \star \star \star}$ Department of Paraclinical Sciences, Faculty of Veterinary Science, University of Pretoria, P/ Bag X04, Onderstepoort 0110, South Africa

${ }^{\dagger \dagger}$ Department of Agriculture and Land Administration, Chief Directorate of Veterinary Services, P/Bag X9064, Ermelo 2350, South Africa

H+Department of Environment and Society, French Agricultural Research Centre for International Development (CIRAD), Avenue Agropolis, 34398 Montpellier, France 
${ }^{\S \S \S}$ Centre for Veterinary Wildlife Studies, Faculty of Veterinary Science, University of Pretoria, P/ Bag X04, Onderstepoort 0110, South Africa

"T"ब Onderstepoort Veterinary Institute, P/Bag X05, Onderstepoort 0110, South Africa

Received 12 September 2008, Revised 29 April 2009, Accepted 2 May 2009

Late in 2007, veterinary, medical and anthropological professionals from Europe and Africa met in a 2-day workshop in Pretoria, South Africa, to evaluate the burden, surveillance and control of zoonotic tuberculosis and brucellosis in sub-Saharan Africa. Keynote presentations reviewed the burden of these diseases on human and livestock health, the existing diagnostic tools, and the available control methods. These presentations were followed by group discussions and the formulation of recommendations.

The presence of Mycobacterium bovis and Brucella spp. in livestock was considered to be a serious threat to public health, since livestock and animal products are the only source of such infections in human beings. The impact of these pathogens on human health appears to be relatively marginal, however, when compared with Mycobacterium tuberculosis infections and drug resistance, HIV and malaria. Appropriate diagnostic tools are needed to improve the detection of $M$. bovis and Brucella spp. in humans. In livestock, the 'test-and-slaughter' approach and the pasteurization of milk, which have been used successfully in industrialized countries, might not be the optimal control tools in Africa. Control strategies should fit the needs and perceptions of local communities. Improved intersectoral and international collaboration in surveillance, diagnosis and control, and in the education of medical and veterinary personnel, are advocated.

At the onset of the 21 st Century, animal production is facing new challenges. Demographic growth, urbanization and economic development contribute considerably to the increasing demand for meat, eggs and other animal products (Steinfeld et al., 2006). The concomitant intensification of animal husbandry and the development of peri-urban systems for livestock production have resulted in increased contact between people and livestock and, consequently, increased risk of some zoonotic diseases (Acha and Szyfres, 2003). Globalization has also increased the problem posed to humans by some pathogens of livestock, since it has been associated with increases in human travel and the international trade and transport of livestock and animal products. In Africa, the encroachment of people and their livestock into wildlife areas, as a result of the pressure on land for grazing and human settlement, has amplified the risk of pathogen transmission between wildlife, livestock and people. The repercussions of these changes - on the transmission and impact of zoonotic diseases on animal and human health and on food safety - are expected to be substantial (Jones et al., 2008).

In Africa, zoonotic tuberculosis and brucellosis, which are caused by pathogens that can infect wildlife, livestock and humans, are poorly controlled in livestock and wildlife and represent a hazard to human health. In late 2007 (19-20 November), a workshop was organized in Pretoria, South Africa, to evaluate the impact of such diseases in sub-Saharan Africa and to formulate recommendations to improve their surveillance and control. Both diseases are 'neglected zoonoses' (WHO, 2006) that are closely associated with livestock production and widely endemic in rural Africa (Cosivi et al., 1995; Sheik-Mohamed and Velema, 1999). Although each may cause severe morbidity in people, and the control of the causative agents in livestock is nearly non-existent in most of Africa, the impact of both diseases on human health, particularly in children and the HIV-infected, is largely unknown. The details of the transmission of the causative agents from wildlife or livestock to humans also remain to be elucidated. The protocol for the Pretoria meeting 
and its main outcomes and recommendations are summarized below.

\section{MATERIALS AND METHODS}

The workshop participants were medical, veterinary and anthropology professionals from Europe and Africa with experience in brucellosis, tuberculosis or zoonotic diseases in general.

The first day of the workshop was dedicated to keynote and research presentations. Each keynote expert was invited to give a presentation on the epidemiology, diagnosis or control of zoonotic tuberculosis and/or brucellosis. Epidemiologists shared their experiences and views on the burden and impact of brucellosis or tuberculosis on local livestock production, wildlife populations and public health. The diagnostic tools that are currently available to detect Brucella or Mycobacterium infections in humans and other animals were reviewed, and their potential and limitations for use in developing countries were discussed. Overviews of the control strategies for these infections in livestock and human populations and on the possible disruption of transmission from livestock/wildlife to human beings were presented. The results of the relevant field research carried out within the framework of the Policy Support Research programme of the Belgian Direction Générale de la Coopération au Développement (i.e. studies on Brucella and M. bovis in livestock in Kenya, Zambia, Ethiopia, Tanzania and in a human-livestock-wildlife interface in Kwazulu-Natal) were also presented. Finally, an anthropological report on the perceptions of rural communities in South Africa on zoonotic diseases was given.

The second day of the workshop was given over to group discussions and the formulation of recommendations. The participants were split into three focus groups, according to their expertise, so that they could discuss (1) the epidemiology and impact, (2) the diagnosis, or (3) the control of zoonotic tuberculosis and brucellosis. Participants from the medical and the veterinary sectors, from Europe and from Africa, were evenly distributed between the three groups. A general discussion took place at the end of the second day, when recommendations on the diagnosis, surveillance, impact assessment and control of Mycobacterium bovis and Brucella in developing countries were formulated. Research priorities and possible collaborations in these fields were also identified.

\section{RESULTS AND DISCUSSION}

\section{Impact and Epidemiology}

Although no accurate estimates (based on comprehensive surveys) exist of the burden on human health posed by zoonotic tuberculosis or brucellosis, the presence of the causative agents in livestock and wildlife populations clearly poses a threat to human well-being. This is particularly the case in those areas (such as most developing countries) where there is no control of the pathogens in livestock or wildlife and where human infection with the pathogens is not monitored. Mycobacterium bovis and Brucella spp. have detrimental effects on the health of livestock (such as abortion, increased calving intervals and weight loss), especially in commercial livestock production (Ameni et al., 2007). These pathogens can also cause morbidity in wildlife, with adverse effects on the tourism industry because of increased mortality and reduced reproduction in game animals and the unattractiveness of sick animals (Michel et al., 2006), and they can limit trade in livestock and animal products.

The main routes of Brucella transmission to people are the consumption of raw animal products and direct contact with infected animals, aborted tissues and discharges. Human brucellosis is mostly an occupational hazard of herdsmen, veterinarians and butchers (particularly those involved in the commercial sector) but also affects people 
who drink raw milk products, such as many African children (Acha and Szyfres, 2003). In humans, the bacteria in the genus Brucella typically provoke an influenza-like syndrome that is rarely correctly diagnosed or reported in Africa. In northern Africa and the Middle East, human brucellosis has been attributed to the presence of $B$. melitensis in livestock (Al Ani et al., 2004; Jennings et al., 2007). Brucella melitensis is usually considered to be the Brucella species with the highest zoonotic potential (Acha and Szyfres, 2003). Although B. abortus appears to be widely distributed among African cattle, $B$. melitensis seems to be relatively rare in sub-Saharan livestock. Of the many sheep and goats tested for this species, using ELISA or the Rose-Bengal plate test (RBPT), in Kenya (D. Mbotha, unpubl. obs.), eastern Zambia (T. Marcotty, unpubl. obs.) and central Ethiopia (K. Amenu, unpubl. obs.), only a few $(<1 \%$ in most instances but $4 \%$ of the Kenyan sheep that were tested) were found seropositive. The seroprevalences recorded, in the same studies, among cattle were slightly higher, ranging from $2.5 \%$ in Ethiopia to $8 \%$ in Zambia and $15 \%$ in Kenya.

Mycobacterium bovis, the cause of zoonotic tuberculosis, is mainly transmitted to humans via the consumption of raw and infected animal products. The possibility of aerial transmission should not be ignored, however, especially in situations where livestock and people share small and enclosed dwellings (Moda et al., 1996). In developing countries in particular, human infection through the manipulation of infected carcasses is another possible route of transmission, at least for hunters and butchers, that needs to be considered (Etter et al., 2006; Wilkins et al., 2008). The impact of $M$. tuberculosis on human health is much more important than the impact of $M$. bovis, and many human infections with $M$. bovis may be misidentified as those of $M$. tuberculosis (Thoen et al., 2006). Compared with the threat posed to humans by $M$. bovis, the emergence of multidrug resistance and, recently, of extended drug resistance in M. tuberculosis in some regions is of much greater concern (Van Helden et al., 2006b). In areas where $M$. tuberculosis is common, zoonotic tuberculosis might even give protection against $M$. tuberculosis, with this benefit outweighing any directly negative impacts of human infection with $M$. bovis (Grange et al., 2001). In HIV-positive and other immunocompromised patients, $M$. bovis infections are probably severe enough to justify widespread control of the bacterium. The effects, on human infection with M. bovis, of inoculation with the Bacille Calmette-Guerin (BCG) vaccine - which is commonly practised in most African countries - are unknown, although such vaccination can itself cause morbidity ('BCGosis') in HIV-positive vaccinees (Hesseling et al., 2006).

The burden and impact of zoonotic tuberculosis and brucellosis on human health, and the contribution such diseases make to the burden of poverty, in terms of both economic and social losses, clearly need to be documented more precisely. The impact on human health and welfare could be quantified using an indicator proposed more than a decade ago by the World Health Organization: the disabilityadjusted life-year (Murray, 1994).

With respect to human disease, the attitudes and perceptions of communities may differ significantly from scientific observations (Foster, 1976; Edginton et al., 2002). Those living in rural communities are often unaware of the risk of human infection from livestock or animal products (M. Otte, unpubl. obs.). In Africa, they often tend to associate disease in livestock and humans with personalistic aetiologies such as misbehaviour or witchcraft (Green, 1998). Although such beliefs should not be generalized, they probably have an important effect on risk behaviours and the acceptability of control measures. In addition, cultural habits (such as the consumption of naturally and deliberately soured milk) might restrain people from taking 
preventive actions (such as the boiling of milk). Qualitative anthropological studies are important components of any research on the prevalence of zoonotic infections in people (Etter et al., 2006) and can contribute substantially to the identification of the risk factors associated with such infections. The findings of such studies should be considered carefully when developing appropriate control strategies.

It would clearly be beneficial if the medical and veterinary professions could collaborate and share their knowledge and resources to assess the burden of endemic zoonoses. Such collaboration should not be limited to outbreak situations (e.g. H5N1 influenza, or Rift Valley fever). The medical profession would, in particular, benefit greatly from an improved knowledge and understanding of the epidemiology of zoonotic tuberculosis and brucellosis. The veterinary sector would, through such collaboration, have a better appreciation of what is expected from them, in terms of controlling the diseases in livestock and/or wildlife in order to assure public health.

\section{Diagnosis}

The tools that are currently available for the diagnosis of tuberculosis and brucellosis include clinical examination, imagery, the isolation and identification of the pathogens (possibly after culture and biochemical differentiation), and molecular and indirect immunological methods (Anon., 2004; Acha and Szyfres, 2003). These tools have different levels of sensitivity and specificity, depending on the condition to be diagnosed (infected, diseased and/or contagious) and various external factors, such as the methods used for specimen collection and storage, cross-reaction with related microorganisms, vaccination history, and immunocompetence.

In humans, the symptoms of brucellosis are not very specific and can easily be confused with those of influenza or malaria (Beers et al., 2006). In livestock, the clinical diagnosis of brucellosis is based mainly on the occurrence of abortion and orchitis and, in more chronic cases, on infertility and joint hygromas (Acha and Szyfres, 2003). Numerous serological tools are available for the confirmation of a presumptive diagnosis of brucellosis (Nielsen, 2002; Konstantinidis et al., 2007; Muma et al., 2007). Although several biochemical, antigenic and molecular tools have been developed to type Brucella isolates (Le Fleche et al., 2006; Fretin et al., 2008), they all require sophisticated equipment and highlyqualified personnel.

The tuberculin skin test remains the easiest and simplest method for the detection of tuberculosis infection in humans and other animals. This test lacks specificity, however, as cross-reactions are observed with environmental mycobacteria and with the BCG vaccine. In addition, the skin test cannot differentiate between $M$. bovis and $M$. tuberculosis infections in humans, or between infection and disease. The interferon- $\gamma$ test, which is based on major purified antigens, is more specific and requires only a single visit. It is, however, also more complicated and more expensive to run than the skin test.

The diagnosis of active tuberculosis in humans is based on anamnesis, symptoms, imagery and the identification of Mycobacteria through smear microscopy or culture. Human tuberculosis caused by $M$. bovis is generally under-diagnosed as a result of a routine sampling method that is not ideal for detecting extra-pulmonary tuberculosis and a lack of typing of the causative pathogens, to species level, during routine diagnosis. In humans, most lesions caused by $M$. bovis are extra-pulmonary (Cosivi et al., 1998) and the accurate diagnosis of this zoonosis often requires biopsies of cervical lymph nodes. The collection of lymph-node biopsies is, however, invasive, difficult to implement in many local hospitals in developing countries, and barely accepted by patients as a routine examination. 
The occurrence of multiple infections and drug resistance in human tuberculosis is becoming increasingly important. More detailed (and hence more expensive) diagnoses are required to ensure optimal treatment of all cases. The genetic characterisation of the mycobacterial strain(s) involved and determining its/their susceptibility to antibiotics (Rigouts et al., 2007) are becoming ever more necessary if every case is to be given effective and quick treatment (Van Helden et al., 2006a). Although biochemical or molecular tools are useful for the characterisation of isolates (Rigouts et al., 1996), they often lack the sensitivity of immunological methods, they are generally expensive and they often require well-equipped laboratories and skilled staff.

The typing of the causative agents of human tuberculosis and brucellosis is particularly important in the development of appropriate control strategies. Typing can allow the identification of the source of infection and, in the case of human tuberculosis, the results of mutation analysis can facilitate the selection of effective drugs. The wider use of existing tools could tremendously improve the quality of diagnosis in sub-Saharan Africa. A transfer of competence, from laboratories with the greatest experience of diagnosis to the relatively inexperienced staff of local, national or regional facilities, is therefore recommended. There is, however, an urgent need for a simple point-of-care test, even if this is not extremely cheap.

In livestock and wildlife, the discrimination between infected and contagious (shedding) animals remains difficult. The detection of shedders with pulmonary tuberculosis might be possible by culturing nasal swabs or even by using 'sniffing' rats (http:// www.newscientist.com/article/dn4488-giantrats-to-sniff-out-tuberculosis.html). Further research is needed to evaluate the sensitivity of the isolation of M. bovis and Brucella spp. from milk.
An increased level of collaboration, between the medical and veterinary sectors across sub-Saharan Africa, is likely to reduce the price of diagnosis and improve its quality. The standardization of the diagnostic methods, and the provision of standard protocols and training to veterinarians, physicians and laboratory technicians are essential. All diagnostic laboratories should also be involved in quality-assurance programmes ('ring tests').

\section{Control}

The eradication of tuberculosis and brucellosis from livestock is expensive since it requires intensive surveillance of the livestock, the slaughter of the infected animals that are detected, and the compensation of those who owned each slaughtered, infected animal. Whereas agricultural policies and practices in developed countries pay farmers substantial compensation for each animal that is culled to control disease, no such schemes exist in most African countries. The general lack of public resources in developing countries seriously hampers such control strategies, leading to unco-ordinated efforts and, eventually, to failure. This, and the fact that rural communities have limited access to healthcare, contribute greatly to local authorities' general neglect of endemic zoonoses derived from infections in livestock, and to farmers' resistance to appropriate interventions. In most instances, the burden posed by such infections in human communities is unknown, the main risk factors are poorly documented, and medical practitioners are poorly aware of, and concerned by, such zoonoses.

According to the concept of 'one health and one medicine' (Schwabe, 1984; Zinsstag and Weiss, 2001), the control of zoonoses is likely to benefit both human and livestock health and, therefore, resources from the medical and the veterinary sectors should be invested in common control strategies (Zinsstag et al., 2005, 2007). Zoonotic tuberculosis and brucellosis also affect 
wildlife conservation and therefore local and national economies (Godfroid, 2002; Michel et al., 2006). While most of the tuberculosis and brucellosis seen in wildlife appears to originate as 'spill-over' from infected livestock, game animals and other wildlife may now play an important role as reservoir hosts and further complicate the epidemiology and control of zoonotic tuberculosis and brucellosis in areas where wildlife, livestock and people co-exist.

If the burden among human communities, livestock and/or wildlife is sufficient to require an intervention, effective control strategies could be developed using existing tools. For the control of zoonotic tuberculosis and brucellosis, it is recommended that strategies to reduce the risk of transmission within livestock and from livestock to human beings be introduced. While eradication programmes, based on a 'test-andslaughter' strategy, are acknowledged not to be ideal for the conditions prevailing in rural Africa (Cosivi et al., 1998), the removal of sick and contagious animals (shedders) could still be useful. Such animals represent a hazard for other, healthy animals, including humans, and have, in any case, reduced productivity. To avoid the aerial transmission of pathogens, livestock should not be concentrated in closed housing and people should not share their dwelling with infected animals. Unfortunately, intensive and/or urban farming units usually hold high concentrations of animals, often in closed environments and in close proximity with people. Even in rural areas, livestock is often held overnight tightly packed into small dwellings, sometimes even with people, to protect it from theft or predators. If the digestive tract is a common route of infection in humans, milk should be boiled or appropriately treated before consumption. Such a measure had a major impact on the occurrence of $M$. bovis in humans in Europe (Acha and Szyfres, 2003).

The vaccination of young stock against brucellosis, using S19 in cattle and Rev 1 in small ruminants, has been extensively and successfully used world-wide (Moriyón et al., 2004). The fact that these vaccines might interfere with the serological diagnosis of brucellosis should not preclude their use in the field, unless the final stages of eradication programmes have been reached. The RB51 vaccine, which does not interfere with serological diagnoses (Cheville, 2000), was reported to lack efficiency and safety compared with S19 and Rev 1 (Anon., 2004). So far, no really effective vaccines are available against $M$. bovis tuberculosis although several research teams have made encouraging observations in this field (Huygen, 2006; Endsley et al., 2007; Hope and VillarrealRamos, 2007). Finally, wildlife should be kept away from farm animals if it is suspected that contact may introduce infection into the livestock.

Many control measures will conflict with the customs and habits of the affected communities and it is therefore essential that the appropriateness of each possible intervention is assessed. The culling of sick animals might be seen as a loss of prestige, for example, while the keeping of livestock outdoors during the night might expose it to too great a risk of theft, and boiling will change the production and flavour of naturally soured milk. When possible, the negative effects of control strategies should be mitigated. The introduction of new probiotic organisms for milk souring may, for example, enable the fermentation of milk to continue as an acceptable practice, while limiting mycobacterial growth and infection (Todorov et al., 2008).

Etter et al. (2006) proposed the use of risk analysis to integrate information from different sources, explore possible pathways of transmission, and identify effective strategies of prevention and control. Public services should determine the disease burden and the risk factors prevailing in the communities ('risk identification'). Subsequently, the communities need to be informed about the risk of the disease, the burden it poses and its control options, using appropriate languages and 
communication tools ('risk communication'). Finally, through a better understanding of the communities' habits and behaviours and the changes the communities are prepared to make, the most appropriate control strategy can be designed. Such an approach may clearly require the involvement of sociologists and anthropologists.

To support control, disease surveillance could focus on 'hot spots' or 'case studies' instead of monitoring entire populations or regions, which is a cumbersome and expensive approach. Disease occurrence in livestock should stimulate appropriate investigations in the local humans (e.g. checks for extra-pulmonary tuberculosis). Regular monitoring for bovine tuberculosis in abattoirs will provide valuable information on the risk to which local people are exposed. Less specific clinical or postmortem indicators, in livestock and in humans, are available for brucellosis. The use of dipsticks (Smits et al., 2003) on patients presenting with acute febrile illnesses and testing negative for malaria might be indicated, allowing the incidence of human brucellosis to be evaluated and appropriate chemotherapy to be recommended. The improved detection of zoonotic tuberculosis and brucellosis in humans is likely to increase medical practitioners' awareness of these diseases.

\section{Conclusions}

To estimate the real burden of zoonotic brucellosis and tuberculosis in sub-Saharan Africa, efficient diagnostic capacity and capability must be present. In this respect, improved collaboration between veterinary and medical laboratories in the region and on the international scene should be encouraged, so that diagnostic methods can be standardized, protocols validated, and quality-assurance programmes implemented. Despite its relatively high costs, the genotyping of the pathogens involved in these zoonoses is recommended, as this should help provide much-needed detail on the epidemiology of the diseases and the pathogens' transmission routes. The development of new diagnostic tools - that would allow the quick and cheap field-based diagnosis of $M$. bovis tuberculosis in livestock, the differential diagnosis of Mycobacterium spp. in humans, the easy detection of shedders, and the survival of the Mycobacterium and Brucella in animal products and in the environment to be followed - would be useful.

Disease burden is not only estimated by disease occurrence. It is also influenced by the severity of the disease on health, wellbeing and rural livelihood. These parameters are not easy to evaluate, as they also depend on the perception people have of zoonoses. It is therefore suggested that disease burden is estimated in various environments using expertise from the veterinary, rural-economy, medical and anthropological disciplines. The burden on wildlife, biodiversity, conservation and tourism also deserves serious attention. A better understanding of the reservoir role played by the various species of wildlife and of the mechanisms of transmission between livestock, people and wildlife would be very beneficial.

The eradication of brucellosis and zoonotic tuberculosis from sub-Saharan Africa is probably not feasible in the immediate future. Therefore, the effects of the various control methods on the epidemiology of, and burden posed by, these infections should be clearly evaluated. The use and the appropriateness of the 'test-and-slaughter' strategy or equivalent agricultural practices, which have already proved to be efficient in many industrialized countries, should be revisited and perhaps gradually introduced to Africa. The slaughtering of shedders only, as an initial approach, might be more appropriate than the culling of all infected animals or, in some cases, entire herds. The use of vaccines, as a way of limiting the impact of Mycobacterium and Brucella infections on livestock and wildlife, 
might be further explored and improved (McNair et al., 2007). Finally, changes in the animal husbandry and behaviour of the humans who live in at-risk communities might be indicated, once the main risk factors have been identified. The control of brucellosis and tuberculosis in wildlife has important ethical connotations. At the moment, there is no agreement whether these infections could or should be controlled. The decision to intervene, in terms of the infections in wildlife, might depend on the risk of spill-over to livestock and human communities and the costs to conservation and tourism. The destruction of contagious wild animals and the vaccination of the most fragile wildlife populations might be considered.

Collaboration between the veterinary and the medical sectors, in the diagnosis, monitoring and control of zoonotic brucellosis and tuberculosis, is strongly encouraged. The sharing of ideas, knowledge and facilities should benefit all of the 'stakeholders', including patients and the owners of livestock. Useful collaborations could be nurtured at undergraduate- and postgraduate-training levels, through, for example, common public-health modules or courses. The transfer of information between the medical and veterinary sectors, on matters related to zoonoses, needs to be improved and the co-ownership of control programmes needs to be encouraged. The much-needed political support may be stimulated by the increasing awareness among policy makers of the potential benefits of such collaboration.

\section{ACKNowledgements. The Belgian Direction} Générale de la Coopération au Développement (DGCD) is thanked for funding the workshop and some of the research activities that were discussed. The workshop was part of a study conducted in the framework of the DGCD's Policy Supporting Research programme (project 9740X). The workshop's participants are grateful to the University of Pretoria's Department of Veterinary Tropical Diseases for hosting the workshop.

\section{REFERENCES}

Acha, P. N. \& Szyfres, B. (2003). Zoonoses and Communicable Diseases Common to Man and Animals: Vol. 1: Bacterioses and Mycoses, 3rd Edn. Washington: Pan American Health Organization.

Al Ani, F. K., El Qaderi, S., Hailat, N. Q., Razziq, R. \& Al Darraji, A. M. (2004). Human and animal brucellosis in Jordan between 1996 and 1998: a study. Revue Scientifique et Technique de l'Office International des Epizooties, 23, 831-840.

Ameni, G., Aseffa, A., Engers, H., Young, D., Gordon, S., Hewinson, G. \& Vordermeier, M. (2007). High prevalence and increased severity of pathology of bovine tuberculosis in Holsteins compared to zebu breeds under field cattle husbandry in central Ethiopia. Clinical and Vaccine Immunology, 14, 1356-1361.

Anon. (2004). Manual of Standards for Diagnostic Tests and Vaccines, 4th Edn. Paris: Office International des Epizooties.

Beers, M. H., Porter, R. S., Jones, V. T., Kaplan, J. L. \& Berkwits, M. (2006). The Merck Manual, 18th Edn. Whitehouse Station, NJ: Merck Research Laboratories.

Cheville, N. F. (2000). Development, testing and commercialization of a new brucellosis vaccine for cattle. Annals of the New York Academy of Sciences, 916, 147-153.

Cosivi, O., Meslin, F. X., Daborn, C. J. \& Grange, J. M. (1995). Epidemiology of Mycobacterium bovis infection in animals and humans, with particular reference to Africa. Revue Scientifique et Technique de l'Office International des Epizooties, 14, 733-746.

Cosivi, O., Grange, J. M., Daborn, C. J., Raviglione, M. C., Fujikura, T., Cousins, D., Robinson, R. A., Huchzermeyer, H. F., de Kantor, I. \& Meslin, F. X. (1998). Zoonotic tuberculosis due to Mycobacterium bovis in developing countries. Emerging Infectious Diseases, 4, 59-70.

Edginton, M. E., Sekatane, C. S. \& Goldstein, S. J. (2002). Patients' beliefs: do they affect tuberculosis control? A study in a rural district of South Africa. International Fournal of Tuberculosis and Lung Disease, 6, 1075-1082.

Endsley, J. J., Hogg, A., Shell, L. J., McAulay, M., Coffey, T., Howard, C., Capinos Scherer, C. F., Waters, W. R., Nonnecke, B., Estes, D. M. \& Villarreal-Ramos, B. (2007). Mycobacterium bovis BCG vaccination induces memory CD $4+\mathrm{T}$ cells characterized by effector biomarker expression and anti-mycobacterial activity. Vaccine, 25, 8384-8394. 
Etter, E., Donado, P., Jori, F., Caron, A., Goutard, F. \& Roger, F. (2006). Risk analysis and bovine tuberculosis, a re-emerging zoonosis. Annals of the New York Academy of Sciences, 1081, 61-73.

Foster, G. M. (1976). Disease etiologies in nonWestern medical systems. American Anthropologist, 78, 773-782.

Fretin, D., Whatmore, A. M., Al Dahouk, S., Neubauer, H., Garin-Bastuji, B., Albert, D., Van Hessche, M., Ménart, M., Godfroid, J., Walravens, K. \& Wattiau, P. (2008). Brucella suis identification and biovar typing by real-time PCR. Veterinary Microbiology, 131, 376-385.

Godfroid, J. (2002). Brucellosis in wildlife. Revue Scientifique et Technique de l'Office International des Epizooties, 21, 277-286.

Grange, J. M., Gandy, M., Farmer, P. \& Zumla, A. (2001). Historical declines in tuberculosis: nature, nurture and the biosocial model. International Fournal of Tuberculosis and Lung Disease, 5, 208-212.

Green, E. C. (1998). Etiology in human and animal ethnomedicine. Agriculture and Human Values, 15, 127-131.

Hesseling, A. C., Rabie, H., Marais, J., Manders, M., Lips, M., Schaaf, H. S., Gie, R. P., Cotton, M. F., van Helden, P. D., Warren, R. M. \& Beyers, N. (2006). Bacille Calmette-Guerin vaccine-induced disease in HIV-infected and HIV-uninfected children. Clinical Infectious Diseases, 42, 548-558.

Hope, J. C. \& Villarreal-Ramos, B. (2007). Bovine TB and the development of new vaccines. Comparative Immunology, Microbiology and Infectious $\overline{\text { Diseases, 31, }}$ $77-100$.

Huygen, K. (2006). DNA vaccines against mycobacterial diseases. Future Microbiology, 1, 63-73.

Jennings, G. J., Hajjeh, R. A., Girgis, F. Y., Fadeel, M. A., Maksoud, M. A., Wasfy, M. O., El-Sayed, N., Srikantiah, P., Luby, S. P., Earhart, K. \& Mahoney, F. J. (2007). Brucellosis as a cause of acute febrile illness in Egypt. Transactions of the Royal Society of Tropical Medicine and Hygiene, 101, 707-713.

Jones, K. E., Patel, N. G., Levy, M. A., Storeygard, A., Balk, D., Gittleman, J. L. \& Daszak, P. (2008). Global trends in emerging infectious diseases. Nature, 451, 990-993.

Konstantinidis, A., Minas, A., Pournaras, S., Kansouzidou, A., Papastergiou, P., Maniatis, A., Stathakis, N. \& Hadjichristodoulou, C. (2007). Evaluation and comparison of fluorescence polarization assay with three of the currently used serological tests in diagnosis of human brucellosis. European Fournal of Clinical Microbiology and Infectious Diseases, 26, 715-721.

Le Fleche, P., Jacques, I., Grayon, M., Al Dahouk, S., Bouchon, P., Denoeud, F., Nöckler, K., Neubauer, H., Guilloteau, L. A. \& Vergnaud, G. (2006). Evaluation and selection of tandem repeat loci for a Brucella MLVA typing assay. $\underline{B M C}$ Microbiology, 6, 9.

McNair, J., Welsh, M. D. \& Pollock, J. M. (2007). The immunology of bovine tuberculosis and progression toward improved disease control strategies. Vaccine, 25, 5504-5511.

Michel, A. L., Bengis, R. G., Keet, D. F., Hofmeyr, M., Klerk, L. M., Cross, P. C., Jolles, A. E., Cooper, D., Whyte, I. J., Buss, P. \& Godfroid, J. (2006). Wildlife tuberculosis in South African conservation areas: implications and challenges. Veterinary Microbiology, 112, 91-100.

Moda, G., Daborn, C. J., Grange, J. M. \& Cosivi, O. (1996). The zoonotic importance of Mycobacterium bovis. Tubercle and Lung Disease, 77, 103-108.

Moriyón, I., Grilló, M. J., Monreal, D., González, D., Marín, C., López-Goñi, I., Mainar-Jaime, R. C., Moreno, E. \& Blasco, J. M. (2004). Rough vaccines in animal brucellosis: structural and genetic basis and present status. Veterinary Research, 35, 138.

Muma, J. B., Toft, N., Oloya, J., Lund, A., Nielsen, K., Samui, K. \& Skjerve, E. (2007). Evaluation of three serological tests for brucellosis in naturally infected cattle using latent class analysis. Veterinary Microbiology, 125, 187-192.

Murray, C. J. (1994). Quantifying the burden of disease: the technical basis for disability-adjusted life years. Bulletin of the World Health Organization, 72, 429-445.

Nielsen, K. (2002). Diagnosis of brucellosis by serology. Veterinary Microbiology, 90, 447-459.

Rigouts, L., Maregeya, B., Traore, H., Collart, J. P., Fissette, K. \& Portaels, F. (1996). Use of DNA restriction fragment typing in the differentiation of Mycobacterium tuberculosis complex isolates from animals and humans in Burundi. Tubercle and Lung Disease, 77, 264-268.

Rigouts, L., Nolasco, O., de Rijk, P., Nduwamahoro, E., van Deun, A., Ramsay, A., Arevalo, J. \& Portaels, F. (2007). Newly developed primers for comprehensive amplification of the $r p o B$ gene and detection of rifampin resistance in Mycobacterium tuberculosis. fournal of Clinical Microbiology, 45, 252-254.

Schwabe, C. W. (1984). Veterinary Medicine and Human Health, 3rd Edn. Baltimore, MD: Williams \& Wilkins.

Sheik-Mohamed, A. \& Velema, J. P. (1999). Where health care has no access: the nomadic populations of sub-Saharan Africa. Tropical Medicine and International Health, 4, 695-707.

Smits, H. L., Abdoel, T. H., Solera, J., Clavijo, E. \& Diaz, R. (2003). Immunochromatographic Brucellaspecific immunoglobulin $M$ and $G$ lateral flow assays for rapid serodiagnosis of human brucellosis. Clinical and Diagnostic Laboratory Immunology, 10, 11411146. 
Steinfeld, H., Gerber, P., Wassenaar, T., Castel, V., Rosales, M. \& de Haan, C. (2006). Livestock's Long Shadow, Environmental Issues and Options. Rome: Food and Agriculture Organization.

Thoen, C., Lobue, P. \& de Kantor, I. (2006). The importance of Mycobacterium bovis as a zoonosis. Veterinary Microbiology, 112, 339-345.

Todorov, S. D., Botes, M., Guigas, C., Schillinger, U., Wiid, I., Wachsman, M. B., Holzapfel, W. H. \& Dicks, L. M. (2008). Boza, a natural source of probiotic lactic acid bacteria. fournal of Applied Microbiology, 104, 465-477.

Van Helden, P. D., Donald, P. R., Victor, T. C., Schaaf, H. S., Hoal, E. G., Walzl, G. \& Warren, R. M. (2006a). Antimicrobial resistance in tuberculosis: an international perspective. Expert Review of Anti-Infective Therapy, 4, 759-766.

Van Helden, P. D., Victor, T. \& Warren, R. M. $(2006 b)$. The 'source' of drug-resistant TB outbreaks. Science, 314, 419-420.

Wilkins, M. J., Meyerson, J., Bartlett, P. C., Spieldenner, S. L., Berry, D. E., Mosher, L. B.,
Kaneene, J. B., Robinson-Dunn, B., Stobierski, M. G. \& Boulton, M. L. (2008). Human Mycobacterium bovis infection and bovine tuberculosis outbreak, Michigan, 1994-2007. Emerging Infectious Diseases, 14, 657-660.

World Health Organization (2006). The Control of Neglected Zoonotic Diseases: a Route to Poverty Alleviation. Report of a foint WHO/DFID-AHP Meeting with the Participation of FAO and OIE, Geneva, 20 and 21 September 2005. Geneva: WHO.

Zinsstag, J. \& Weiss, M. G. (2001). Livestock diseases and human health. Science, 294, 477.

Zinsstag, J., Schelling, E., Wyss, K. \& Mahamat, M. B. (2005). Potential of cooperation between human and animal health to strengthen health systems. Lancet, 366, 2142-2145.

Zinsstag, J., Schelling, E., Roth, F., Bonfoh, B., de Savigny, D. \& Tanner, M. (2007). Human benefits of animal interventions for zoonosis control. Emerging Infectious Diseases, 13, $\underline{527-531 .}$ 